\title{
Neonatal interventions differently affect maternal care quality and have sexually dimorphic developmental effects on corticosterone secretion
}

\author{
Natividade de Sá Couto-Pereira ${ }^{a, *}$, Charles Francisco Ferreira ${ }^{b, c, 3}$, Carine Lampert ${ }^{a}$, \\ Danusa Mar Arcego ${ }^{a}$, Ana Paula Toniazzo ${ }^{a}$, Juliana Rombaldi Bernardi ${ }^{c, 4}$, \\ Diego Carrilho da Silva a , Eduardo Von Poser Toigo a , Luisa Amalia Diehl ${ }^{\text {a, }}$, \\ Rachel Krolow $^{\mathrm{a}, 2}$, Patrícia Pelufo Silveira ${ }^{\mathrm{b}, \mathrm{c}}$, Carla Dalmaz ${ }^{\mathrm{a}, \mathrm{b}}$ \\ a Programa de Pós-Graduação em Ciências Biológicas: Bioquímica, Departamento de Bioquímica, Universidade Federal do Rio Grande do Sul (UFRGS), Porto \\ Alegre, RS, Brazil \\ b Programa de Pós-Graduação em Ciências Biológicas: Neurociências, Universidade Federal do Rio Grande do Sul (UFRGS), Porto Alegre, RS, Brazil \\ ${ }^{\mathrm{c}}$ Núcleo de Estudos da Saúde da Criança e do Adolescente, Hospital de Clínicas de Porto Alegre (HCPA), Universidade Federal do Rio Grande do Sul (UFRGS), \\ Porto Alegre, RS, Brazil
}

\section{A R T I C L E I N F O}

\section{Article history:}

Received 19 July 2016

Received in revised form

15 September 2016

Accepted 3 October 2016

Available online 4 October 2016

\section{Keywords:}

Maternal care

Behavior inconsistency

Neonatal handling

Maternal separation

Central oxytocin

Corticosterone

\begin{abstract}
A B S T R A C T
Neonatal handling $(\mathrm{H})$ and maternal separation (MS) both induce changes in maternal care, but the contribution of these changes to the behavioral and neurochemical outcomes of the offspring remains unclear, as studies often find opposite results concerning the frequency of maternal behaviors, particularly in the MS paradigm. In this study, behavior displayed by $\mathrm{H}$, MS and non-handled (NH) Wistar rat dams were observed during the first 10 days after birth. A tentative assessment of the quality of maternal care was made, using a previously reported score that reflects behavior fragmentation and inconsistency. Central oxytocin levels and hippocampal synaptic plasticity markers were also evaluated in dams, immediately after litter weaning. In adulthood, male and female offspring were subjected to a contextual stressinduced corticosterone challenge to provide further information on the impact of early interventions on neuroendocrine parameters. We found that while both $\mathrm{H}$ and MS interventions induced an increase in the amount of pup-directed behavior, MS dams displayed a more fragmented and inconsistent pattern of care, reflecting poorer maternal care quality. Interestingly, an increase in oxytocin levels was observed only in $\mathrm{H}$ dams. While $\mathrm{H}$ offspring did not differ from $\mathrm{NH}$, MS males and females showed marked differences in corticosterone secretion compared to controls. Our results suggest that briefly removing the pups from the nest alters maternal care quantity but not quality and increases central oxytocin, while long separations appear to increase low quality maternal care and change neuroendocrine responses in adult offspring in a sex-specific manner.
\end{abstract}

@ 2016 ISDN. Published by Elsevier Ltd. All rights reserved.

\footnotetext{
* Corresponding author at: Departamento de Bioquímica, Universidade Federal do Rio Grande do Sul (UFRGS), Porto Alegre, RS CEP: 90035-003, Brazil. E-mail address: natividade.pereira@gmail.com (N.d.S. Couto-Pereira).

1 Present address: Departamento de Enfermagem, Universidade Federal de Ciências da Saúde de Porto Alegre, Porto Alegre, RS, Brazil.

2 Present address: Programa de Pós-Graduação em Saúde e Comportamento, Universidade Católica de Pelotas (UCPel), Pelotas, RS, Brazil.

3 Programa de Pós-Graduação em Ciências da Saúde: Ginecologia e Obstetrícia (PPGGO), Faculdade de Medicina (FAMED), Hospital de Clínicas de Porto Alegre (HCPA), Universidade Federal do Rio Grande do Sul (UFRGS), Porto Alegre, RS, Brazil.

4 Departamento de Nutrição, Faculdade de Medicina (FAMED), Universidade Federal do Rio Grande do Sul (UFRGS), Porto Alegre, RS, Brazil.
}

\section{Introduction}

Maternal care is an essential part of the development in many animal species. Rat pups, due to their altricial nature, display little interaction with the surrounding environment. Therefore, it is through maternal behavior, which is highly affected by environmental conditions, that pups perceive their surroundings during the early stages of development (Francis and Meaney, 1999). It has been proposed that maternal behavior prepares the offspring to respond to the environment by adequately programming their hypothalamus-pituitary-adrenal (HPA) axis response to stress (Liu et al., 1997). In fact, enhanced maternal care improves resilience in 
the offspring in rodents (Coutellier et al., 2008; Champagne et al., 2003; van Hasselt et al., 2012; Liu et al., 1997; Singh-Taylor et al., 2015) and humans (Brauer et al., 2016), whereas abnormal or deficient care increases the vulnerability to stress-related disorders, both in humans (Kim et al., 2016) and animals (Cirulli et al., 2003; Murgatroyd et al., 2015; Singh-Taylor et al., 2015).

In rodents, removing pups from the nest, either for brief (handling) or long periods (maternal separation), increases the frequency of pup-directed behaviors by dams (Bodensteiner et al., 2012; Macrí et al., 2004; Pryce et al., 2001), although some studies present opposite results (Aguggia et al., 2013; Boccia et al., 2007; Reis et al., 2014). It has been proposed that the long-term consequences neonatal interventions have on the offspring, particularly concerning the adaptive programming of the HPA axis by early handling in rodents, result from the changes that this intervention induces on the dams behavior (Cirulli et al., 2003; Denenberg, 1999; Kuhn and Schanberg, 1998; Liu et al., 1997; Meaney et al., 1985). However, recent studies have suggested that these effects may be linked to the novelty exposure component that comprises the handling procedure, rather than directly resulting of increased maternal care (Reeb-Sutherland and Tang, 2011; Tang et al., 2006). The impact that altered behavior in dams has on the outcomes of MS offspring was also questioned in an interesting study that used a split-litter design (Macrì et al., 2008); unfortunately, in that study, only male offspring was studied. These recent reports evaluated maternal care mostly by quantifying the frequency of pup-directed behaviors. It has been recently suggested that increased maternal care, when analyzed purely quantitatively, is not necessarily favorable to litter development (Dalle Molle et al., 2012; Murgatroyd and Nephew, 2013; Reeb-Sutherland and Tang, 2012). This idea contributes to the discussion of why MS offspring, despite having over caring mothers, have such deleterious stress responses as adults (Aisa et al., 2007; Desbonnet et al., 2008; Diehl et al., 2014, 2011; Lajud et al., 2012; Rivarola and Suárez, 2009). In addition, raises the question of how much and what maternal care features are relevant to the long time consequences of handling and maternal separation on offspring. In this scenery, despite the importance of the mother-pup interaction on offspring development, only a few studies have focused on the mother in these models, so the mechanisms underlying different forms of maternal behavior after brief or long separations between dams and pups are scarcely understood (Stamatakis et al., 2015). Since the mother and the pup form a dyad (Francis and Meaney, 1999), any manipulation of their interaction will necessarily affect both, and should be studied from both perspectives.

Maternal care in rats occurs in bouts. A maternal bout consists on a series of organized events, beginning with entering the nest and gathering the pups, followed by nursing and licking the pups and ending when the dam leaves the nest (Leon et al., 1978). Therefore, it is plausible to think that erratic and unpredictable maternal care may be a source of stress for pups (Ivy et al., 2008; Molet et al., 2016); in accordance, abnormal parental care in humans has been associated with the development of several psychopathies (Kim et al., 2016). Considering this, Ivy et al. (2008) have proposed a behavioral score to measure the quality of maternal care and showed that an early-life stress model, which results in increased anxiety and HPA axis hyperactivity in the offspring, also produced fragmented and inconsistent behavior in the dam.

The neuropeptide oxytocin is involved in mediating the bond between mother and pup in mammal species (Nagasawa et al., 2012; Pedersen and Boccia, 2003; Uvnäs-Moberg, 1997). Elevated levels of oxytocin receptor have been associated with high levels of licking and nursing in the arched-back position (Francis et al., 2000). Interestingly, $\mathrm{H}$ dams also exhibited increased levels of this receptor in several brain structures, including the hippocampus, medial preoptic area and central amygdala (Stamatakis et al., 2015), thus suggesting that oxytocin signaling may be involved in mediating the changes in maternal care induced by neonatal interventions.

It has been previously reported that rats exposed to maternal separation exhibit some behavior consistent with high vulnerability to anxiety disorders, namely post-traumatic stress syndrome-like characteristics (Diehl et al., 2011). Particularly, these animals seem to process repeatedly retrieved memories differently when compared to animals that were left undisturbed in the neonatal period (Diehl et al., 2014; Zalosnik et al., 2014). Several reports have also pointed that basal and stress-induced corticosterone secretion is different in males and females that were repeatedly separated from the dam in the neonatal period (reviewed by Rees et al., 2006).

The reports regarding effects of neonatal interventions on maternal care and the effects of short and long separations from dams induce on offspring show inconsistent results. Hovewer, the evaluation of the sequence and daily distribution of dams behavior is beginning to be considered as an important tool to better understand the maternal behavior (Ivy et al., 2008; Molet et al., 2016; Peña and Champagne, 2013; Reis et al., 2014). Taking that in consideration, here we studied the quality of maternal care in Wistar rats in an attempt to contribute to the knowledge of how maternal nurturing may participate in the modulation of the offspring ability to face stressful events later in life. Additionally, parameters related to synaptic plasticity (brain derived neurotrophic factor - BDNF and synaptophysin) were measured in the dam's hippocampus, and oxytocin levels were determined in the cerebral spinal fluid (CSF) at weaning. Corticosterone circulating levels after a stress challenge were determined in the adult offspring.

\section{Methods}

\subsection{Subjects}

Primiparous pregnant Wistar rats bred at our animal facility were randomly selected $(n=27$ for behavioral measurements and $n=45$ for biochemical evaluations). At gestational day 17-18, they were single-housed in home cages made of Plexiglas $(65 \times 25 \times 15 \mathrm{~cm})$ with sawdust-covered floors and kept in a controlled environment (lights on between 07:00 h and 19:00 h, temperature at $22 \pm 2{ }^{\circ} \mathrm{C}$, food and water provided). All litters were randomly culled to six to eight pups within $24 \mathrm{~h}$ after birth. The day of birth was considered day 0 and weaning was performed on postnatal day 21 (PND 21), when offspring males and females were separated and randomly housed 3-4 per cage, and were then left undisturbed until the behavioral tests, except for cage cleaning. All animal treatments were approved by the institutional Research Ethics Committee (CEUA-UFRGS \#23844) and followed the Brazilian Law regarding the use of animals (Federal Law 11.794/2008) and the Guidelines for the Care and Use of Mammals in Neuroscience and Behavioral Research (National Research Council 2003).

\subsection{Neonatal intervention models}

Each litter had its own glove to be manipulated with, to avoid the spread of odors between nests. From birth to weaning, cage cleaning was performed only when necessary, similarly for all groups: dirty sawdust was carefully removed from the cage, avoiding the nest area, and replaced with clean sawdust.

Non-handled group (NH): pups and dams were left undisturbed until weaning, except for cage cleaning.

Neonatal Handling group $(\mathrm{H})$ : pups were gently removed from their home cages and placed into a clean cage lined with clean paper towels, inside an incubator set to $32^{\circ} \mathrm{C}$. After $10 \mathrm{~min}$, pups were returned to their dams. This procedure was carried out in the first 
10 days of life, between 12:00 h and 13:00 h, after which litters were left undisturbed until weaning, except for cage cleaning.

Maternal separation group (MS): same protocol as the H group, except pups remained in the incubator for $3 \mathrm{~h}$ (between 14:15 $\mathrm{h}$ and $17: 30 \mathrm{~h})$.

\subsection{Behavioral tests}

\subsubsection{Maternal care observation}

Maternal behavior observations were performed for all motherlitter pairs during the neonatal intervention period (PND 1-10), as described in Champagne et al. (2003). The total number of observed litters was 27 ( $\mathrm{NH}: \mathrm{n}=10, \mathrm{H}: \mathrm{n}=8, \mathrm{MS}: \mathrm{n}=9$ ). The observations were performed at regular times (cycles), twice in the dark phase (06:00 $\mathrm{h}$ and 20:00 h) and three times in the light phase $(10: 00 \mathrm{~h}$, 13:00 $\mathrm{h}$ and $17: 30 \mathrm{~h}$ ). In each observation cycle, maternal behavior was monitored every $3 \mathrm{~min}$, during $72 \mathrm{~min}$, for a total of 25 observations per cycle per day for each dam, which yielded a total of 1250 observations for each dam in the 10 days of experiment.

Behavior was observed live by one of three different researchers that had previously been trained together. The computed behaviors were: licking, nursing in arched-back, blanket or supine posture, mother in or off nest, retrieving pups, nest building, mother drinking/eating. The frequency of each behavior in each cycle and day was determined and computed into a databank which was later subjected to revision. For "cycle" analyses, the sum of frequencies of each behavior for the 10 days was used (total number of observations: 250/cycle/dam). For "day" analyses, frequencies from the 5 cycles of each day were added (total number of observations: 125/day/dam).

2.3.1.1. Behavioral inconsistency. Behavioral inconsistency score was assessed as a qualitative measure of maternal care, based on Ivy et al. (2008). Maternal behavior experimental tables were analyzed for each cycle, each day; whenever behaviors changed from one observation to the next in the cycle, a grade " 1 " was given. Grades for each cycle were added and divided by 24 (total possible number of behavior changes between the 25 observations), resulting in a "behavioral inconsistency score" which varies between 0 and 1. The higher the score, the more fragmented and inconsistent the maternal care. Transitions between the following behaviors were considered: nursing, licking, retrieving pups, nest building, away from pups, eating/drinking.

\subsubsection{Flinch-jump test}

A flinch-jump test (Lehner et al., 2010) was performed on female and male adult offspring (PND 90-100) that were subjected to the neonatal interventions described here to assess possible differences in painful stimulus perception that could affect the results of the stress challenge. A total of 26 males (NH: $n=11, H: n=8, M S: n=7$ ) and 22 females (NH: $n=7, H: n=8, M S: n=7$ ) was used. The test was performed in a wooden lidded apparatus $(28 \times 26 \times 23 \mathrm{~cm})$, with one transparent plastic wall, and a grid floor of parallel 0.1 $\mathrm{cm}$ caliber stainless steel bars spaced $1.0 \mathrm{~cm}$ apart wired to a shock generator. Rats were placed individually in the box and allowed to habituate for $1 \mathrm{~min}$, after which footshocks were delivered in ascending followed by descending order $(0.1 \mathrm{~mA}, 1 \mathrm{~s}$ duration, 0.1-0.9 mA range), every 10s. The 'flinch' and 'jump' thresholds were defined for each rat as the average current $(\mathrm{mA})$ at which the animals first (ascending series) or last (descending series) presented each behavior.

\subsubsection{Stress challenge}

Naïve male and female rats, aged between 90 and 100 days, subjected to the neonatal interventions described here, were used in this experiment; average weight: $364 \pm 9 \mathrm{~g}$ (males) and $241 \pm 5 \mathrm{~g}$ (females). Experiments took place between 9 and 12 a.m. Only one rat of each sex from the same litter was exposed to each experimental condition in this task. Animals were placed in the apparatus described above and allowed to explore it for $3 \mathrm{~min}$, after which they received three $0.8 \mathrm{~mA} 1 \mathrm{~s}$-duration footshocks, $30 \mathrm{~s}$ interval between shocks (training session); the frequency of jumps in response to each footshock was recorded for each animal. Rats remained 1 min more in the apparatus, and were then placed back in their home cages. Twenty-four hours after the exposure to the aversive stimulus, a subset of animals was re-exposed to the same context for $5 \mathrm{~min}$; $15 \mathrm{~min}$ after the end of the challenge session, animals were quickly euthanized using a guillotine and trunk blood samples were collected for corticosterone levels evaluation. Another subset of non-challenged animals was euthanized $24 \mathrm{~h}$ after training and trunk blood was collected to assess basal corticosterone levels.

\subsection{Biochemical analysis}

\subsubsection{Oxytocin assay}

Immediately after litter weaning (PND 21), a different subset of dams was anesthetized using $120 \mathrm{mg} / \mathrm{kg}$ ketamine $\mathrm{HCl}$ (Dopalen: Agribrands, Campinas, SP, Brazil) and $16 \mathrm{mg} / \mathrm{kg}$ xylazine (Anasedan: Agribrands, Campinas, SP, Brazil). CSF samples were obtained by a magna cistern puncture and stored at $-80^{\circ} \mathrm{C}$ for latter usage.

Oxytocin levels in the CSF were measured by enzyme immunoassay, using a commercial kit (Oxytocin EIA Kit, Assay designs, USA), following the manufacturer's instructions. The total number of dams used for this assay was $20(\mathrm{NH}: \mathrm{n}=7, \mathrm{H}: \mathrm{n}=7$, MS: $\mathrm{n}=6$ ). Results are expressed as pg oxytocin/ml CSF.

\subsubsection{Hippocampal analysis}

Immediately after litter weaning (PND 21), another subset of dams was quickly euthanized using a guillotine. Twenty-five dams were used for this experiment (NH: $n=9, \mathrm{H}: \mathrm{n}=9, \mathrm{MS}: \mathrm{n}=7$ ). Hippocampi were carefully dissected on ice and stored at $-80^{\circ} \mathrm{C}$ until analyses. Tissue was homogenized 1:10 in a lysis buffer $\mathrm{pH}$ 7.9, containing $137 \mathrm{mM} \mathrm{NaCl}, 2.5 \mathrm{M} \mathrm{KCl}, 10 \mathrm{mM}$ Hepes, $0.6 \mathrm{~mm}$ EDTA, $1 \%$ SDS, $10 \%$ glycerol and $1 \%$ protease inhibitor cocktail (Roche, Switzerland) and a $15 \mathrm{~min} 4000 \mathrm{rpm}$ centrifugation was performed to clear the homogenate, which was stored at $-20^{\circ} \mathrm{C}$ until use. Total protein content was determined using the method described by Lowry et al. (1951).

2.4.2.1. BDNF assay. For BDNF analysis, a sandwich ELISA was performed on the hippocampus homogenate, using a commercial kit (BDNF Emax ${ }^{\circledR}$ Immunoassay system, Promega, USA), as previously described (Arcego et al., 2016). Results are expressed as pg BDNF/mg protein. $s$

2.4.2.2. Western blot. Hippocampus homogenate samples were loaded in poliacrylamide gels (loading gel: $4.5 \%$ acrylamide; running gel: $10 \%$ acrylamide) in equal protein concentrations ( $40 \mu \mathrm{g}$ of total protein/lane). After electrophoresis, proteins were transferred (XCell SureLock ${ }^{\circledR}$ Mini-Cell, Invitrogen) to nitrocellulose membranes ( $1 \mathrm{~h} 10 \mathrm{~min}$ at $50 \mathrm{~V}$ in transfer buffer [ $48 \mathrm{mM}$ Trizma, $39 \mathrm{mM}$ glycine, $20 \%$ methanol, and $0.25 \%$ SDS] ) and blots were then blocked for $2 \mathrm{~h}$ in Tris-buffered saline with $5 \% \mathrm{~m} / \mathrm{v}$ non-fat dry milk. Blots were incubated overnight at $4{ }^{\circ} \mathrm{C}$ in blocking solution containing one of the following antibodies: anti-synaptophysin (1:200, Santa Cruz, USA) and anti- $\alpha$-tubulin (1:1000, Sigma-Aldrich, USA). Secondary antibody (peroxidase-conjugated anti-rabbit IgG $[1: 1000$, Merck-Millipore, Germany]) was diluted in blocking solution and incubated for $2 \mathrm{~h}$ at room temperature. Blots were developed using a chemiluminescence Amersham ${ }^{\mathrm{TM}}$ ECL kit (GE Healthcare, UK) and 
exposed on a Kodak@ film. The intensity of bands was quantified by densitometric analysis using the ImageJ software (National Institutes of Health, USA). Results were quantified as the ratio of the optical density (OD) of the protein of interest to that of $\alpha$-tubulin (Sigma-Aldrich, USA) of the same sample in the same blot, and expressed in percentage of control (NH group). The total number of samples used for this assay was $17(\mathrm{NH}: n=5, \mathrm{H}: \mathrm{n}=6, \mathrm{MS}: \mathrm{n}=6)$.

\subsubsection{Corticosterone assay}

Offpring serum corticosterone levels were determined as described previously (Diehl et al., 2007), from serum obtained as described in subsection 2.3.3. Briefly, corticosterone was extracted with ethyl acetate and analyzed with a commercial enzymelinked immunosorbent assay (ELISA) kit (Corticosterone ELISA kit, Cayman Chemical Co., USA), following the manufacturer's instructions. Results are expressed as ng corticosterone $/ \mathrm{ml}$ serum. The total number of serum samples used for this assay was 59: non-challenged males - $15(\mathrm{NH}: \mathrm{n}=5, \mathrm{H}: \mathrm{n}=4$, MS: $n=6)$; non-challenged females - $12(\mathrm{NH}: \mathrm{n}=4, \mathrm{H}: \mathrm{n}=4$, MS: $\mathrm{n}=4)$; challenged males $-16(\mathrm{NH}: \mathrm{n}=5, \mathrm{H}: \mathrm{n}=5$, MS: $n=6)$; challenged females $-16(N H: n=6, H: n=5$, MS: $n=5)$.

\subsection{Statistical analyses}

Data was analyzed using the software SPSS version 16.0. Repeated measures ANOVA (neonatal intervention as between subjects factor) was performed to compare frequencies of maternal behaviors or mean behavioral inconsistency factor throughout the intervention period (day) and throughout the day (cycle), using the Greenhouse-Geisser correction whenever data did not meet the sphericity assumption. One-way ANOVA (neonatal intervention as between subjects factor) was performed for each cycle independently whenever a statistically significant interaction between cycle and neonatal intervention was found, and also for total frequency of maternal behavior, dams' biochemical data and percentage of males in the litters. Two-way ANOVA (neonatal intervention and sex as factors) was used to analyze the flinch-jump test results. Three-way ANOVA (neonatal intervention, sex and challenge as factors) was performed for the corticosterone results, followed by one-way ANOVA to compare groups. Tukey or LSD post-hoc analyses were used when appropriate. Data is expressed as mean \pm standard error of the mean (SEM). Statistical significance was set at $\mathrm{p}<0.05$. For the inconsistency behavior data, results were not considered for animals that presented scores that were more than 2 standard deviations from the mean (three cases, one from each group).

\section{Results}

\subsection{Maternal care}

Maternal behavior displayed by $\mathrm{NH}, \mathrm{H}$ and MS dams was recorded during the first 10 days postpartum, 5 times a day. Results are presented quantitatively, first. For the frequency of pup licking, a significant interaction between neonatal intervention and observation period (cycle) was found $[\mathrm{F}(8,96)=5.84, \mathrm{p}<0.001]$, as depicted in Fig. 1A. This behavior was more frequent when $\mathrm{H}$ and MS pups were returned to the nests, after their respective intervention procedure [i.e., at $13: 00 \mathrm{~h}$ for $\mathrm{H}$ group $(\mathrm{p}=0.006)$ and at 17:30 h for MS group $(\mathrm{p}<0.001)$ ], similarly to previous reports (Liu et al., 1997; Pryce et al., 2001). MS and H dams also showed an overall increase in the total frequency of licking compared to $\mathrm{NH}$ dams $[F(2,24)=6.24, p=0.007$; Tukey post-hoc, $p<0.05]$, but no differences between them $(\mathrm{p}=0.815)$. A significant similar interaction was also observed for the frequency of nursing in the arched-back posture $[F(5.84,70.05)=7.73, p<0.001]$. A marked increase of this behavior was observed in MS dams in the 17:30 and 20:00 cycles ( $\mathrm{p}<0.001$ for both), as displayed in Fig. 1B. MS dams also presented an overall increase in arched-back nursing compared to $\mathrm{H}$ dams $[\mathrm{F}(2,24)=4.85, \mathrm{p}=0.017$; Tukey post-hoc, $\mathrm{p}=0.019]$. While no differences were found between groups in the total frequency of nursing $[F(2,24)=1.41, p=0.26]$, an interaction was observed between intervention and observation time $[F(6.16,73.86)=3.70$, $\mathrm{p}=0.003$ ]. MS decreased their frequency of nursing $(\mathrm{p}=0.005)$, particularly in the 10:00 observation cycle (Fig. 1C). Total frequency of mother off nest was not different between the groups either $[F(2,24)=0.41, p=0.67]$, but an interaction intervention $x$ cycle was found $[F(5.723,68.67)=4.38, p=0.001]$. Again, MS dams in the $10: 00$ observation were significantly different from controls $(p=0.006)$, which explains the decrease in nursing seen in this cycle (Fig. 1D).

As expected (Champagne et al., 2003; Leon et al., 1978; Reis et al., 2014), maternal care gradually decreased through the days (main effect of day, $\mathrm{p}<0.05$ for all behaviors analyzed), but no significant interactions between intervention and postpartum day were found ( $p>0.05$ for all behaviors analyzed; data not shown).

Lately attention has been given to qualitative maternal care analysis as a complimentary and rather informative tool (Ivy et al., 2008; Molet et al., 2016; Reis et al., 2014), hence we also calculated a behavioral inconsistency score that reflects the fragmentation of pup-oriented behaviors in dams, depicted in Fig. 1E. Concerning this score, a significant interaction was found between neonatal intervention and cycle $[\mathrm{F}(8,84)=4.04, \mathrm{p}<0.001]$. MS dams exhibited a higher score of inconsistency in the two observation cycles that followed the intervention ( $17: 30$ cycle, $p=0.001 ; 20: 00$ cycle, $\mathrm{p}=0.05$ ), as well as an overall increased score compared to controls $[\mathrm{F}(2,21)=4.41, \mathrm{p}=0.025$; Tukey post-hoc, $\mathrm{p}=0.024]$. $\mathrm{H}$ dams also had a small increase in their inconsistency score after the intervention $(p=0.004)$, but overall were not different from $\mathrm{NH}$ dams $(p=0.14)$. Since MS dams exhibited a very high frequency of arched-back nursing, and dams frequently exchange nursing positions (Stern, 1997), when analyzing behavioral inconsistency, we did not consider changes between nursing positions to calculate the score, thus avoiding a possible false positive result regarding MS mothers.

Dams frequently direct nurturing behavior towards male pups (Moore and Morelli, 1979) and differences have been found, not only on maternal care, but also in the offspring glucocorticoid receptor methylation status depending on the sex composition of the litter (Kosten and Nielsen, 2014). Therefore, we compared the percentage of male pups in our litters to exclude a possible effect of the litter composition on our results. No significant differences were found in the percentage of males in $\mathrm{NH}, \mathrm{H}$ and MS litters ( $49 \pm 6 \%, 45 \pm 7 \%, 49 \pm 7 \%$, respectively; $\mathrm{p}=0.867$ ), thus eliminating this confounding factor.

Oxytocin is strongly related with maternal care (Nagasawa et al., 2012; Uvnäs-Moberg, 1997). Increased expression of oxytocin receptor have been associated with high levels of licking and nursing in the arched-back position (Francis et al., 2000) and was also found in $\mathrm{H}$ dams (Stamatakis et al., 2015), while intracerebroventricular infusion of an oxytocin receptor antagonist resulted in decreased licking and arched-back nursing (Pedersen and Boccia, 2003). Therefore, to provide further information about neurochemical modulation of $\mathrm{H}$ and MS mothers' behavior, we measured CSF levels of oxytocin in dams, at PND 21 (Fig. 2). A marked increase of oxytocin was observed in $\mathrm{H}$ dams when compared with both $\mathrm{NH}$ and MS dams $[\mathrm{F}(2,19)=6.635, \mathrm{p}=0.007$, Tukey post hoc $\mathrm{p}<0.05]$.

Maternal care is essentially an innate behavior as can be demonstrated, for example, by injecting oxytocin in the cerebral ventricles of virgin females (Pedersen et al., 1982). In accordance, behavioral stability has been observed across consecutive litters of the same dam (Champagne et al., 2003). However, as demonstrated here and 


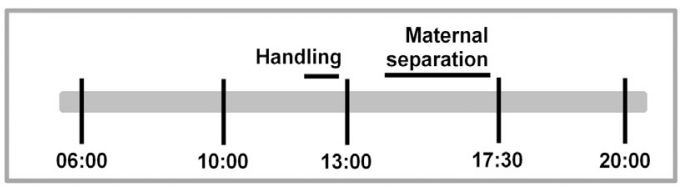

A

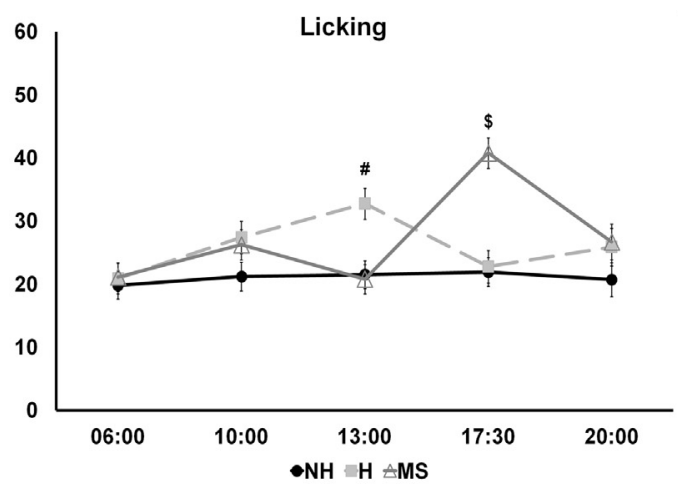

C

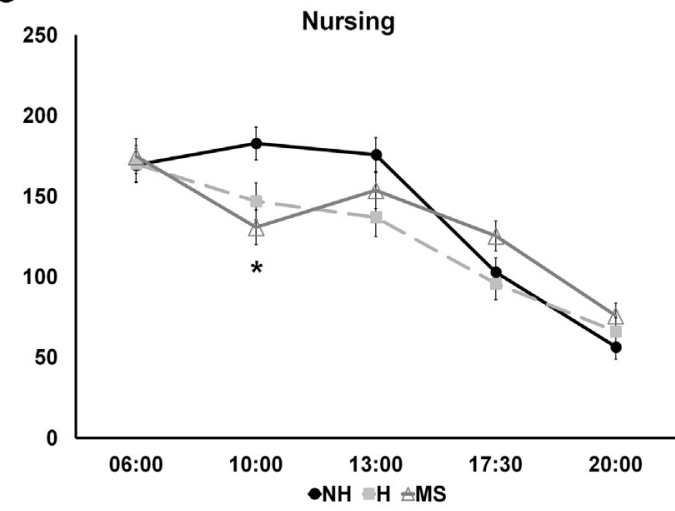

B

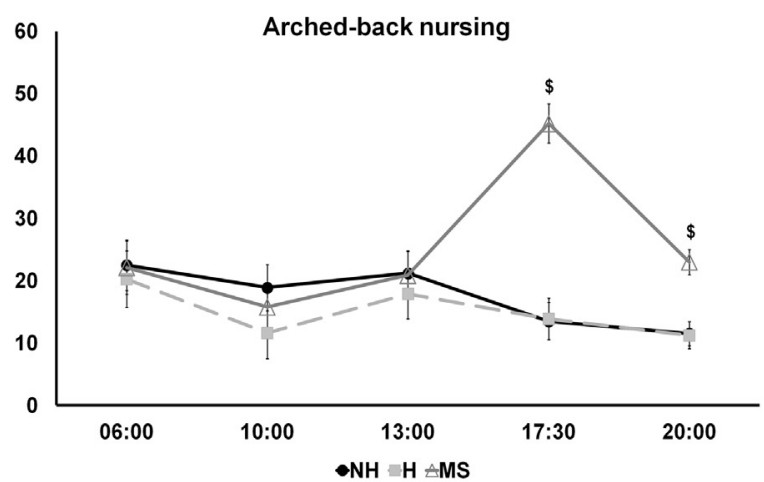

D

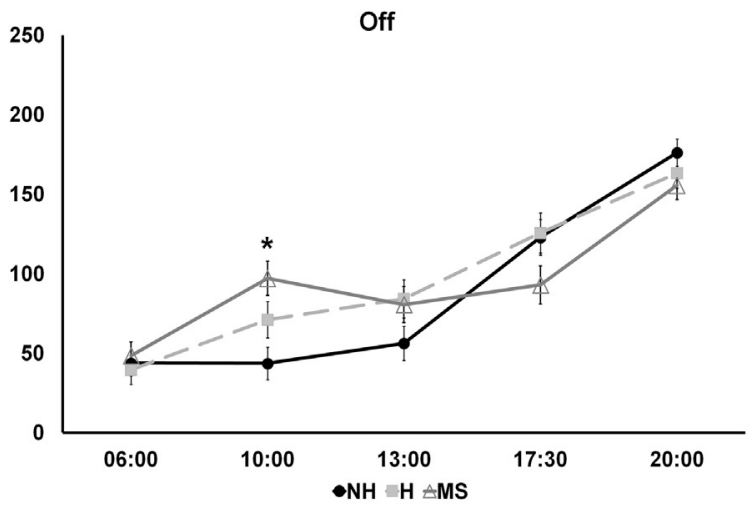

$E$

Behavioral Inconsistency Score

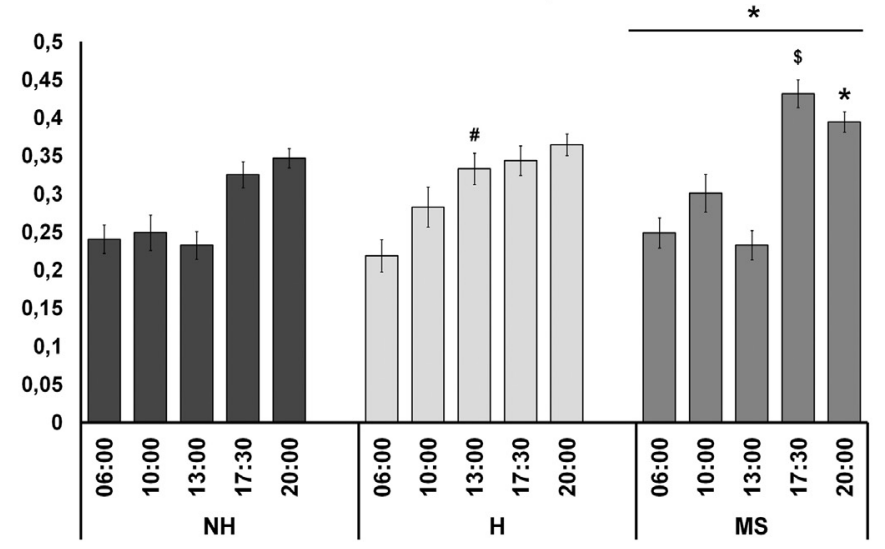

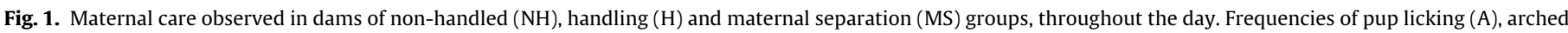

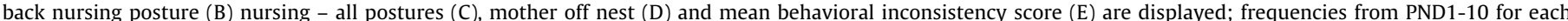

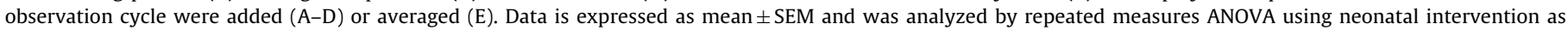

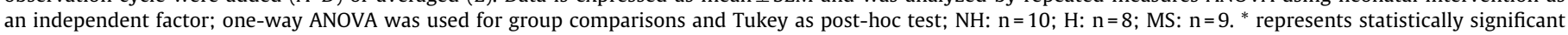

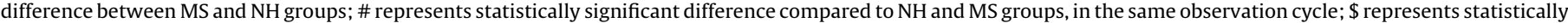
significant difference compared to $\mathrm{NH}$ and $\mathrm{H}$ groups, in the same observation cycle. $\mathrm{p}$ Values are presented in subsection 3.1 .

in other studies (Bodensteiner et al., 2012; Macrí et al., 2004; Pryce et al., 2001; Reis et al., 2014), dams adapt their behavior to meet pups' demands (Pereira and Ferreira, 2016) and to the environmental conditions. Some adaptations seem to persist to subsequent maternal experiences, even if the source of stress is removed (Wong et al., 2011), implying that a learning component also exists in maternal care (Scanlan et al., 2006). Taking that into account, we examined BDNF and synaptophysin in the hippocampus of dams 


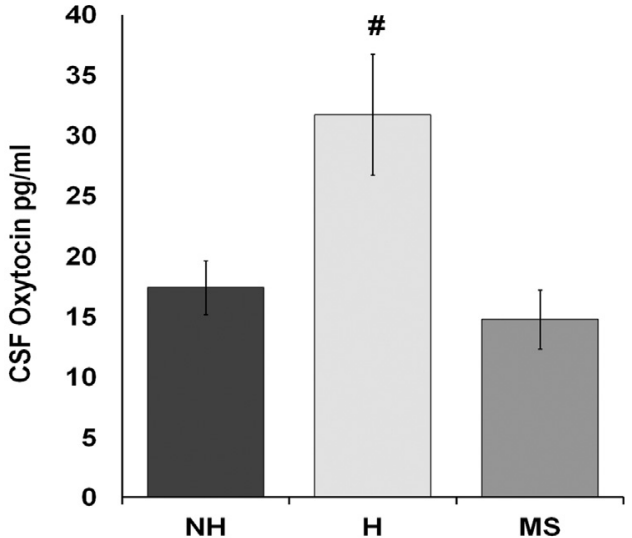

Fig. 2. Oxytocin levels $(\mathrm{pg} / \mathrm{ml})$ in the cerebral spinal fluid (CSF) of dams of nonhandled $(\mathrm{NH})$, handling $(\mathrm{H})$ and maternal separation (MS) groups, at PND 21 , immediately after litter weaning. Data is expressed as mean \pm SEM and was analyzed by one-way ANOVA using neonatal intervention as an independent factor, and Tukey as post-hoc test; $\mathrm{NH}: \mathrm{n}=7 ; \mathrm{H}: \mathrm{n}=7 ; \mathrm{MS}: \mathrm{n}=6$. \# represents statistically significant difference compared to the other groups. p Values are presented in subsection 3.1.

subjected to the described postpartum interventions (Fig. 3). No significant differences between interventions were found either for $\operatorname{BDNF}(\mathrm{p}=0.681$ ) or synaptophysin ( $\mathrm{p}=0.839$ ). No significant differences in $\alpha$-tubulin OD were found among groups either $(p=0.617)$, which assures that protein loading was similar in all samples. These results suggest that plasticity related to maternal care is not dependent on BDNF or synaptophysin in the hippocampus. However, conclusions are preliminary, since, to our knowledge, this is the first study to measure BDNF and synaptophysin levels in the hippocampus of $\mathrm{H}$ and MS dams.

\subsection{Effects of neonatal interventions on corticosterone secretion in adult offspring}

Males and females subjected the neonatal interventions were tested during adulthood in an attempt to provide information on the impact of maternal care on the offspring's HPA axis function,
Table 1

Flinch and jump thresholds in response to electric footshocks in adult male and female offspring that were subjected to non-handled, handling and maternal separation procedures in the neonatal period.

\begin{tabular}{llll}
\hline & & flinch threshold $(\mathrm{mA})$ & jump threshold $(\mathrm{mA})$ \\
\hline \multirow{2}{*}{ males } & Non-Handled & $0.20 \pm 0.02$ & $0.65 \pm 0.04$ \\
& Handling & $0.15 \pm 0.02$ & $0.64 \pm 0.04$ \\
& Maternal Separation & $0.14 \pm 0.02$ & $0.61 \pm 0.04$ \\
females & Non-Handled & $0.14 \pm 0.03$ & $0.53 \pm 0.07$ \\
& Handling & $0.15 \pm 0.02$ & $0.44 \pm 0.04$ \\
& Maternal Separation & $0.11 \pm 0.01$ & $0.50 \pm 0.06$
\end{tabular}

Data is expressed mean \pm SEM and was analyzed by two-way ANOVA using neonatal intervention and sex as factors, and Tukey as post-hoc test; males $-\mathrm{NH}$ : $\mathrm{n}=11, \mathrm{H}$ : $n=8$, MS: $n=7$, females $-\mathrm{NH}: \mathrm{n}=7, \mathrm{H}: \mathrm{n}=8$, MS: $n=7$. Females had a lower jump threshold than males. p Values are presented in subsection 3.2

particularly how corticosterone levels would change in response to the exposure to a conditioned aversive context.

First, a flinch-jump test (Lehner et al., 2010) was performed on the adult offspring to determine possible differences in pain sensitivity in the different groups and, consequently, differences in how the electric stimulus would be perceived and reflected as increased corticosterone levels in the stress challenge task (Table 1). No significant interaction or main effects were found for the flinch threshold in this test (interaction: $p=0.387$ ), but a main effect of sex was found for the jump threshold $[F(1,36)=10.522, p=0.003]$. Since females had a slightly lower jump threshold than males, we chose a current intensity in which mainly all animals exhibited a jump response $(0.8 \mathrm{~mA})$, to minimize differences in stimulus sensitivity among groups.

A different subset of $\mathrm{NH}, \mathrm{H}$ and MS adult offspring was submitted to the stress challenge task. A series of three $0.8 \mathrm{~mA}$ footshocks was applied; no significant differences between sexes in the frequency of jump in response to the three footshocks were found (one-way ANOVA: $p=0.124$ ), which supported our choice of current intensity for this experiment. Twenty-four hours later, approximately half the animals were re-exposed to the footshock context for 5 min (challenged). Serum corticosterone levels were determined at a single time point $(15 \mathrm{~min}$ after the end of the conditioned stimulus exposure) and compared with samples from animals that received the footshocks $24 \mathrm{~h}$ before, but were not re-exposed to the context (non-challenged). Results are depicted in Fig. 4. A signifi-
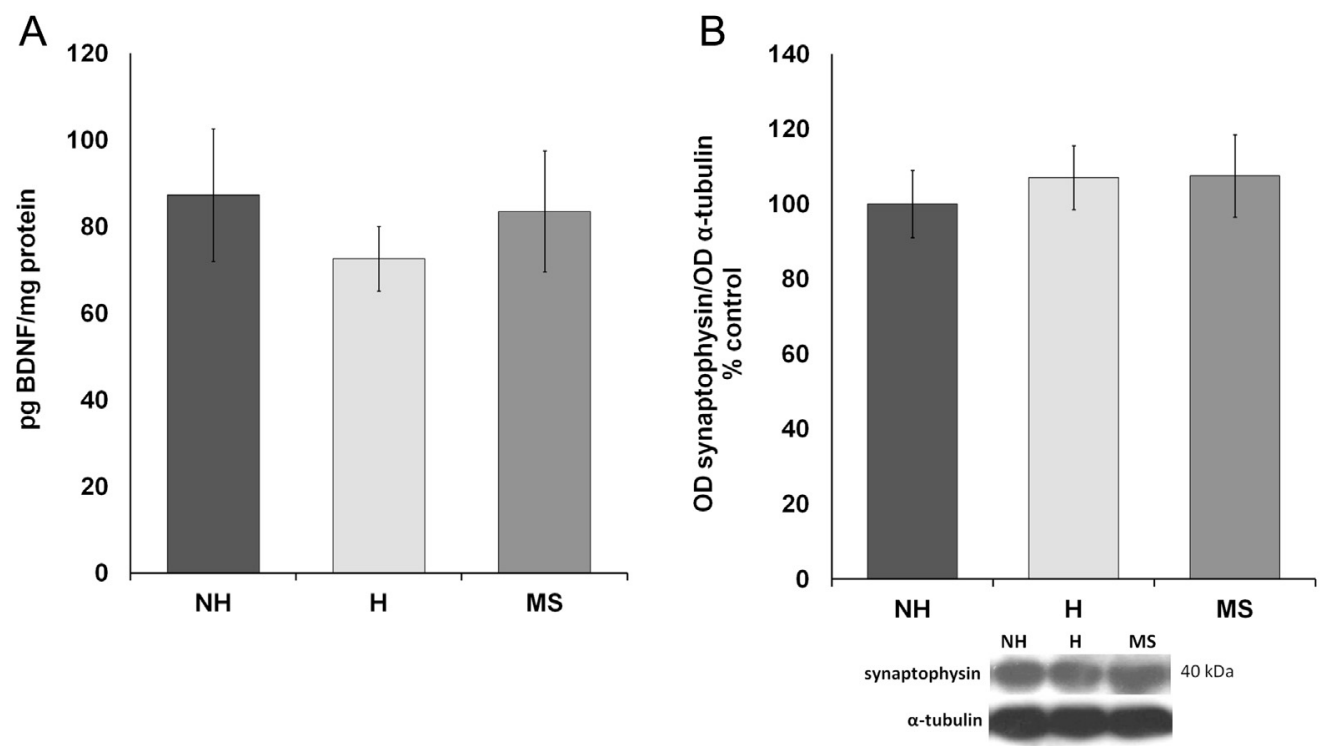

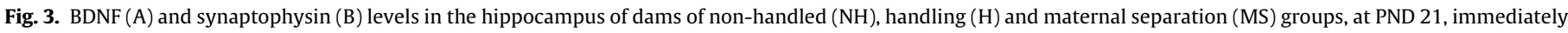
after litter weaning. No significant differences were found; BDNF $-\mathrm{NH}: \mathrm{n}=9, \mathrm{H}: \mathrm{n}=9, \mathrm{MS}: \mathrm{n}=7$; synaptophysin $-\mathrm{NH}: \mathrm{n}=5, \mathrm{H}: \mathrm{n}=6, \mathrm{MS}: \mathrm{n}=6$. 


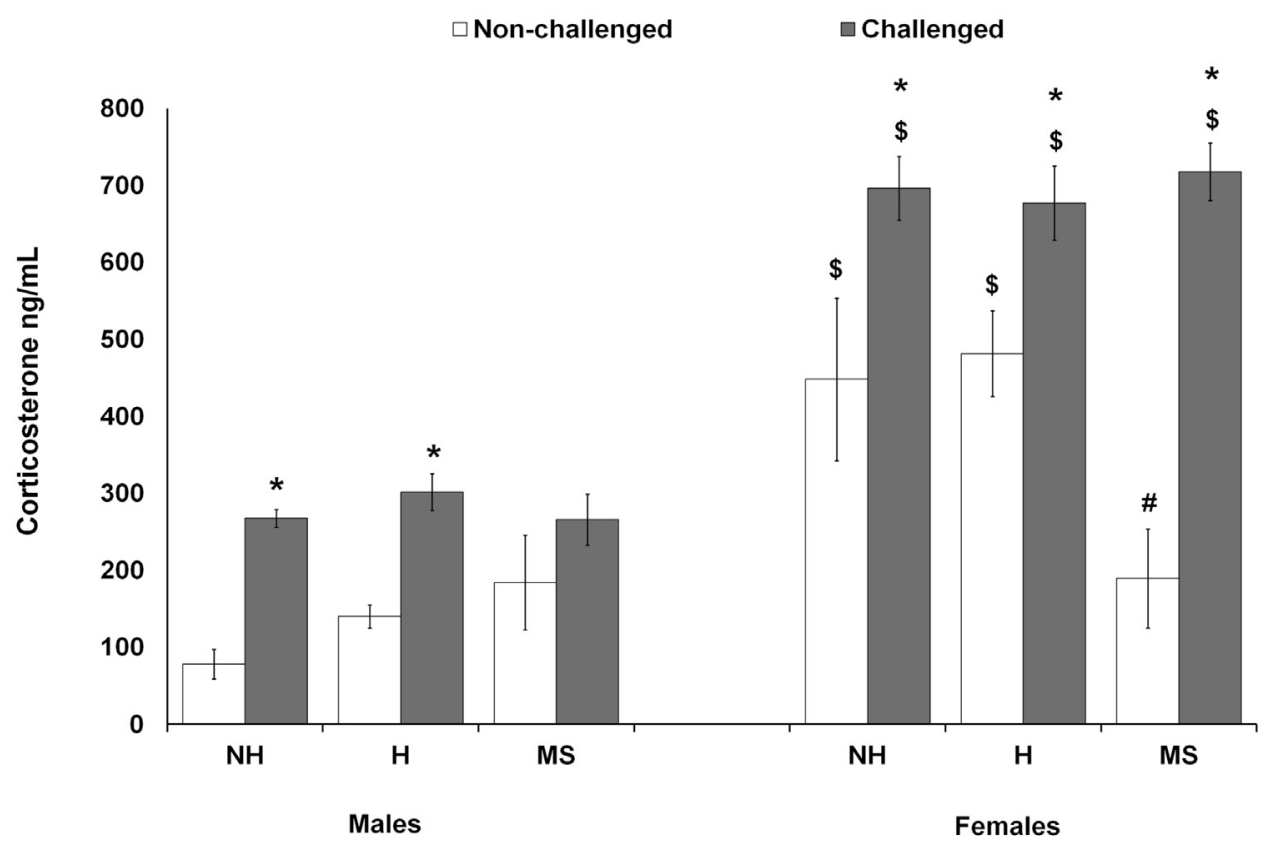

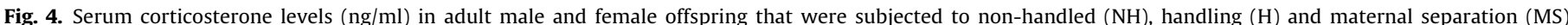

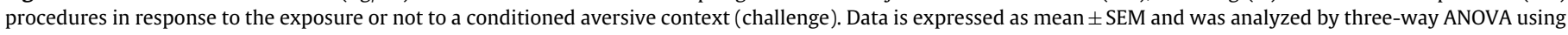

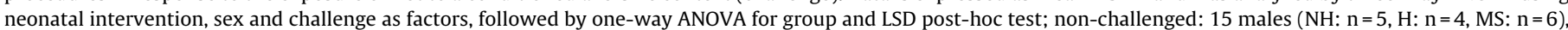

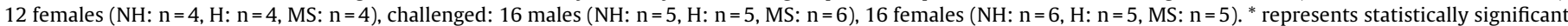

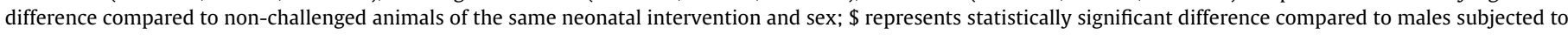

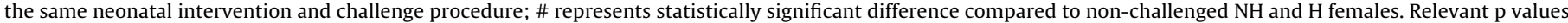
are presented in subsection 3.2.

cant interaction between sex, neonatal intervention and challenge was found $[F(2,47)=6.015, p=0.005]$. In general, females and challenged animals had higher corticosterone levels. A subsequent one-way ANOVA revealed that all groups had a significant increase in corticosterone levels after being challenged $(p<0.05)$ except for MS males $(p=0.184)$; non-challenged MS females had lower corticosterone levels compared to $\mathrm{NH}$ and $\mathrm{H}$ females $(\mathrm{p}=0.001$ and $\mathrm{p}<0.001$, respectively). Interestingly, non-challenged MS males and females were not different $(\mathrm{p}=0.939)$.

It is worthy to disclosure that our non-challenge corticosterone levels may not represent basal levels, as animals had been presented with aversive stimuli the day before and thus there is no guarantee that once removed from the vivarium, a stress response was not triggered. We did however make sure that animals were euthanized as quickly as possible once out of the vivarium (less than $5 \mathrm{~min}$ ).

\section{Discussion}

Disrupting the mother-pup interaction results in changes in maternal care in rats, and early interventions such as neonatal handling and maternal separation, have been studied to assert the influence of the environment on the pup's development, especially concerning the functioning of the HPA axis (Lajud et al., 2012; Liu et al., 1997; Macrí et al., 2004). The outcomes that these two interventions have on the offspring have been intensively studied, but their impact on maternal care and how this contributes to the consequences observed on the offspring are not clear, particularly concerning the paradigms that involve long pup separations. Here, we showed, for the first time, that MS Wistar rat mothers present high fragmentation of maternal care, while $\mathrm{H}$ dams only show a small and single increase in behavioral inconsistency, when compared to NH mothers. We also evaluated central oxytocin and hippocampal BDNF and synaptophysin, and we found increased CSF oxytocin in dams whose pups were handled. Addi- tionally, contextual stress-induced corticosterone was evaluated on the adult offspring and group and sex-specific responses to stress were observed.

The circadian distribution of maternal care in NH mothers was very constant, and the frequency of behaviors that are strongly correlated with improved care, like licking and arched-back nursing, hardly changed throughout the day. H dams exhibited similar daily patterns, except for an increase in pup licking, which is in accordance with previous reports (Liu et al., 1997; Stamatakis et al., 2015). Other slight variations in maternal behavior pattern presented by $\mathrm{H}$ dams did not reach significance, but were similar to those observed by Reis et al. (2014). As for MS mothers, their behavior changed considerably compared to $\mathrm{NH}$ dams, with intervention-induced high increases in licking and arched-back nursing and increased time spent away from pups and consequently less time spent nursing in the morning (10:00 observation). The observed increase in arched-back nursing in MS mothers did not imply increased total frequency of nursing, but a switch from the more common blanket posture to the arched-back posture, probably induced by the demanding pups (Stern, 1997). In summary, long separations seem to induce an acute increase in maternal care (Pryce et al., 2001) that is not maintained throughout the day, and more importantly, alter the circadian pattern of pup-related behaviors, particularly in the light phase. The transient nature of the increase in MS dams care and the fact that it occurs in the light phase may possibly explain why some studies reported a decrease in nurturing frequency in these dams (Boccia et al., 2007). Apart from the sustained increase in arched-back nursing in MS mothers observed in the 20:00 cycle, no differences between groups were observed in the two nocturnal observations (6:00 and 20:00), which was expected since nursing is more common during the light phase in rats (Champagne et al., 2003).

The sequence and pattern of maternal care seem to be relevant factors to assess the quality of this behavior and its impacts on the offspring development (Ivy et al., 2008; Molet et al., 2016; Reis 
et al., 2014). Based on this fact, we also performed a qualitative analysis of maternal care of dams, by scoring the inconsistency and fragmentation of their behavior (Ivy et al., 2008). In H dams, we found only a small increase in behavioral inconsistency in the cycle after the procedure, which could be explained by the findings of Liu et al. (1997) that $\mathrm{H}$ dams had shorter but more frequent nest bouts than controls. MS mothers, on the other hand, showed higher fragmentation of maternal behavior, which also occurred in mothers subjected to the stress paradigm reported by Ivy et al. (2008). The increase in behavior fragmentation is not due to alternations between nursing postures, which frequently occur in rat as reflex responses to pup demands (Stern, 1997), since we did not consider them to determine the inconsistency score. Frequent intervals between licking bouts may contribute to this result, since rat dams usually exhibit rather short licking bouts (Champagne et al., 2003), which could count as behavior changes in our analysis and increase the inconsistency score. However, the total frequency of licking was similar among all groups in the late night observation, and the inconsistency score remained high for MS mothers in this period. Inconsistent care displayed by these dams may result from a conflict between attending demanding pups and dealing with its own stress and, despite being quantitatively high, may not be tuned with the pups needs (Pereira and Ferreira, 2016). We should consider that $\mathrm{NH}$ mothers show an increase in fragmentation of their maternal behavior late in the afternoon. As such, the increase in fragmentation in the MS mothers could be an exacerbation of this behavior. It would be interesting to perform further studies addressing the point of handling late in the afternoon.

Several studies have shown that oxytocin is involved in the mediation of maternal behavior, particularly by enhancing the dam's motivation to respond to pups (Bridges, 2015). We reported here that brief separations from pups induce a high and long lasting increase in the levels of this neuropeptide in the dams CSF, which could be related to the increase in maternal care observed in this group. One limitation of this study is that, since behavior was recorded at PND1-10, and biochemical analyses were performed on PND21, it is possible that some biochemical effect could have changed by the time of euthanasia. However, Stamatakis et al. (2015) have shown an increase in the expression of oxytocin receptors in several brain areas in $\mathrm{H}$ dams, which lasted up to PND 22. Oxytocin levels appear to be inversely correlated with depressive-like symptoms in the postpartum period, in humans (Moura et al., 2016). MS mothers in our study did not exhibit an increase in oxytocin production at the analysis day, despite their higher frequency of maternal activities, a neurobehavioral pattern that has been previously referred to as "attenuated nursing efficiency" by Murgatroyd and Nephew (2013), regarding another model of maternal stress. Rat mothers that experienced long separations from their pups exhibit increased anxiety-like (Aguggia et al., 2013; Maniam and Morris, 2010) and depression-like behaviors (Boccia et al., 2007; Maniam and Morris, 2010; von Poser Toigo et al., 2012). Together with the inconsistent maternal care and the absence of increased oxytocin levels reported here (compared to H dams), our study offers further support to the suggestion that maternal separation may correlate with postpartum depression in humans (Boccia et al., 2007; von Poser Toigo et al., 2012). Human mothers also show an association between poor childcare and depression/anxiety (Kim et al., 2016).

Changes in the HPA axis reactivity have already been reported in adult MS and H animals (Colman et al., 2015; Diehl et al., 2007; Kalinichev et al., 2002; Lajud et al., 2012; Llorente-Berzal et al., 2012; Rees et al., 2006), with a variety of responses that range from no differences to either increase or decrease in the intervention groups. Such inconsistencies may result from a dependency of the HPA response on the MS protocol used, age, strain and sex of the animals and the type of stressor (reviewed by Rees et al., 2006).
Although a similar approach was used by Pryce et al. (2003) on early deprivation (isolation) Wistar rat offspring, to our knowledge, this is the first report of changes in MS circulating corticosterone levels in response to the exposure not to a stressor per se, but to a conditioned aversive context, which represents a psychological stressor. These changes may have implications on how males and females that were separated from the mother during the neonatal period retrieve and reconsolidate aversive contextual memories, since glucocorticoids strongly affect these processes (Cai et al., 2006).

Our results concerning circulating levels of corticosterone appear to coincide with the quality of care our dams offered to their offspring. H mothers did not show marked differences compared to $\mathrm{NH}$, except for the increased licking behavior, which consequently results in a small increase in the behavior inconsistency score in the period when it was observed. Similarly, $\mathrm{H}$ adult offspring did not differ from controls in their corticosterone response, either when non-challenge or when exposed to the aversive environment, which is in accordance with previous studies which also submitted $\mathrm{H}$ animals (Wistar and Long-Evans rats) to different stressors (Colman et al., 2015; Kalinichev et al., 2002). It is important to mention that animals that were handled in the neonatal period do show several behavioral and neurochemical alterations (Liu et al., 1997; Marcolin et al., 2012; Singh-Taylor et al., 2015), but context-induced endocrine stress response was not altered here. On the other hand, a strong increase in behavioral fragmentation was observed in MS dams, and the offspring also exhibited very different corticosterone secretion patterns compared to controls. Male MS rats did not increase corticosterone production in response to the aversive context exposure, since their basal levels were already high; this may correlate with the increase in anxiety-like behavior and memory processing changes previously reported in MS male Wistar rats (Aisa et al., 2007; Diehl et al., 2011, 2014). MS females, on the other side, had lower basal corticosterone levels than controls, as previously reported also in Wistar rats (Diehl et al., 2007; Llorente-Berzal et al., 2012), and showed a marked increase after the challenge.

It is worthy to state that only one corticosterone measure in response to a specific type of stressor was used in this report, so the conclusions we draw concerning neuroendocrine responses in $\mathrm{H}$ and MS animals are limited. However, changes reported here are consistent with other studies (Colman et al., 2015; Diehl et al., 2007; Kalinichev et al., 2002). In addition, our goal was to study the contribution of maternal care to the long-term consequences of neonatal interventions, to which our experiment provided interesting insights.

Two important factors interact in the MS procedure: first, the pups lose tactile contact with the mother and are kept without a nutrition source for $3 \mathrm{~h}$ per day (in our MS model, heating is assured and the pups are not separated from their siblings, as occurs in some deprivation studies); second, the dam increases the quantity and decreases the quality of care it provides to the litter, as shown here. Conditions listed in the first item have been shown to affect the HPA long-term regulation (Suchecki et al., 1993) and other aspects of MS pups development have been attributed specifically to the lack of tactile stimulation during the separation period (Kuhn and Schanberg, 1998). Interestingly, our adult MS females and males, which received the same neonatal treatment, exhibited very different corticosterone secretion patterns when challenged. Even when non-challenged, these animals show opposite differences towards their respective controls. This could be an effect that arose later in life as a consequence of modulation of corticosterone synthesis by sexual hormones, which are modified by early life interventions (Viveros et al., 2010) or it could be a result of estrogen effects on neurodevelopment during the neonatal phase, as some studies with maternal deprivation have suggested (Oomen et al., 2009). While the work by Oomen et al. (2009) appeared to exclude the impact 
of maternal care on their results, Macrì et al. (2008) proposed that increased maternal care in MS dams could partially compensate the deleterious effects of the separation. Hence, the role of altered maternal care on MS offspring neurodevelopment remains controversial. Again, a purely quantitative approach was taken in these studies. The amount of licking rat mothers perform on pups has predictive value when applied to handling studies (Liu et al., 1997; van Hasselt et al., 2012; Macrì et al., 2008; Meaney et al., 1985). However, there appears to be a ceiling effect in the benefits of tactile stimulation to the pups, as determined by studies that use artificial rearing (Lomanowska and Melo, 2016), so the stronger increases in this behavior observed in MS dams may not necessarily be advantageous to the offspring; also, the pattern of care, rather than just the frequency, appears to be important, and may better correlate with neurobehavioral outcomes of neonatal interventions.

Quality assessment of maternal care in this report points that $\mathrm{H}$ mothers, in addition to providing higher care for their pups, did so without creating a high disruption in the pattern of "normal" maternal care; they also had a marked increase in the central production of oxytocin. Their adult offspring did not show differences in aversive context-induced corticosterone secretion compared to controls. On the contrary, the increase in maternal behavior observed in MS mothers was not accompanied by an increase in oxytocin production and occurred in a fragmented and inconsistent manner, which we propose, could be an additional source of stress for MS pups and contribute to the long-term negative consequences observed in these animals in this and other studies. Future studies should better address the interaction between pup sex and the quality of maternal care. This could contribute to a better understanding of sexual dimorphic long-term effects of early interventions.

\section{Funding}

This work was financially supported by the Conselho Nacional de Desenvolvimento Científico e Tecnológico (CNPq) and Coordenação de Aperfeiçoamento de Pessoal de Nível Superior (CAPES). The funding agencies had no involvement in data collection/analysis or in the preparation/submission of this manuscript.

\section{Acknowledgement}

The authors wish to deeply thank Dr. Maria Elisa Calcagnotto for her assistance with language editing and proofreading of the manuscript.

\section{References}

Aguggia, J.P., Suárez, M.M., Rivarola, M.A., 2013. Early maternal separation: neurobehavioral consequences in mother rats. Behav. Brain Res. 248, 25-31, http://dx.doi.org/10.1016/j.bbr.2013.03.040.

Aisa, B., Tordera, R., Lasheras, B., Del Río, J., Ramírez, M.J., 2007. Cognitive impairment associated to HPA axis hyperactivity after maternal separation in rats. Psychoneuroendocrinology 32 (3), 256-266, http://dx.doi.org/10.1016/j. psyneuen.2006.12.013.

Arcego, D.M., Krolow, R., Lampert, C., Toniazzo, A.P., Berlitz, C., Lazzaretti, C., Schmitz, F., Rodrigues, A.F., Wyse, A.T.S., Dalmaz, C., 2016. Early life adversities or high fat diet intake reduce cognitive function and alter BDNF signaling in adult rats: interplay of these factors changes these effects. Int. J. Dev. Neurosci. 50, 16-25, http://dx.doi.org/10.1016/j.ijdevneu.2016.03.001.

Boccia, M.L., Razzoli, M., Vadlamudi, S.P., Trumbull, W., Caleffie, C., Pedersen, C.A., 2007. Repeated long separations from pups produce depression-like behavior in rat mothers. Psychoneuroendocrinology 32, 65-71, http://dx.doi.org/10. 1016/j.psyneuen.2006.10.004.

Bodensteiner, K.J., Ghiraldi, L.L., Miner, S.S., 2012. Differential effects of short- and long-term early maternal separation on subsequent maternal behavior in rats. J. Gen. Psychol. 139 (2), 78-99, http://dx.doi.org/10.1080/00221309.2012. 661377.

Brauer, J., Xiao, Y., Poulain, T., Friederici, A.D., Schirmer, A., 2016. Frequency of maternal touch predicts resting activity and connectivity of the developing social brain. Cereb. Cortex, http://dx.doi.org/10.1093/cercor/bhw137, epub ahead of print.

Bridges, R.S., 2015. Neuroendocrine regulation of maternal behavior. Front. Neuroendocrinol. 36, 178-196, http://dx.doi.org/10.1016/j.yfrne.2014.11.007.

Cai, W.H., Blundell, J., Han, J., Greene, R.W., Powell, C.M., 2006. Postreactivation glucocorticoids impair recall of established fear memory. J. Neurosci. 26 (37), 9560-9566, http://dx.doi.org/10.1523/JNEUROSCI.2397-06.2006.

Champagne, F.A., Francis, D.D., Mar, A., Meaney, M.J., 2003. Variations in maternal care in the rat as a mediating influence for the effects of environment on development. Physiol. Behav. 79, 359-371, http://dx.doi.org/10.1016/S00319384(03)00149-5.

Cirulli, F., Berry, A., Alleva, E., 2003. Early disruption of the mother-infant relationship: effects on brain plasticity and implications for psychopathology. Neurosci. Biobehav. Rev. 27, 73-82, http://dx.doi.org/10.1016/s01497634(03)00010-1.

Colman, J.B., Laureano, D.P., Reis, T.M., Krolow, R., Dalmaz, C., Benetti, C.S., Silveira, P.P., 2015. Variations in the neonatal environment modulate adult behavioral and brain responses to palatable food withdrawal in adult female rats. Int. J. Dev. Neurosci. 40, 70-75, http://dx.doi.org/10.1016/j.ijdevneu.2014.11.003.

Coutellier, L., Friedrich, A.C., Failing, K., Würbel, H., 2008. Variations in the postnatal maternal environment in mice: effects on maternal behaviour and behavioural and endocrine responses in the adult offspring. Physiol. Behav. 93, 395-407, http://dx.doi.org/10.1016/j.physbeh.2007.09.008.

Dalle Molle, R., Portella, A.K., Goldani, M.Z., Kapczinski, F.P., Leistner-Segala, S., Salum, G.A., Manfro, G.G., Silveira, P.P., 2012. Associations between parenting behavior and anxiety in a rodent model and a clinical sample: relationship to peripheral BDNF levels. Transl. Psychiatry 2, e195, http://dx.doi.org/10.1038/ tp.2012.126.

Denenberg, V.H., 1999. Commentary: is maternal stimulation the mediator of the handling effect in infancy? Dev. Psychobiol. 34 (1), 1-3, http://dx.doi.org/10. 1002/(SICI)1098-2302(199901)34:1<1:AID-DEV2>3.0.CO;2-U.

Desbonnet, L., Garrett, L., Daly, E., McDermott, K.W., Dinan, T.G., 2008. Sexually dimorphic effects of maternal separation stress on corticotrophin-releasing factor and vasopressin systems in the adult rat brain. Int. J. Dev. Neurosci. 26, 259-268, http://dx.doi.org/10.1016/j.ijdevneu.2008.02.004.

Diehl, L.A., Silveira, P.P., Leite, M.C., Crema, L.M., Portella, A.K., Billodre, M.N., Nunes, E., Henriques, T.P., Fidelix-da-Silva, L.B., Heis, M.D., Gonçalves, C.A., Quillfeldt, J.A., Dalmaz, C., 2007. Long lasting sex-specific effects upon behavior and S100b levels after maternal separation and exposure to a model of post-traumatic stress disorder in rats. Brain Res. 1144, 107-116, http://dx.doi. org/10.1016/j.brainres.2007.01.084.

Diehl, L.A., Alvares, L.O., Noschang, C., Engelke, D., Andreazza, A.C., Gonçalves, C.A.S., Quillfeldt, J.A., Dalmaz, C., 2011. Long-lasting effects of maternal separation on an animal model of post-traumatic stress disorder: effects on memory and hippocampal oxidative stress. Neurochem. Res. 37, 700-707, http://dx.doi.org/10.1007/s11064-011-0660-6.

Diehl, L.A., Couto-Pereira, N.S., Laureano, D.P., Benitz, A.N.D., Noschang, C., Ferreira, A.G.K., Scherer, E.B., Machado, F.R., Henriques, T.P., Wyse, A.T.S., Molina, V., Dalmaz, C., 2014. Contextual fear conditioning in maternal separated rats: the amygdala as a site for alterations. Neurochem. Res. 39, 384-393, http://dx.doi. org/10.1007/s11064-013-1230-x.

Francis, D.D., Meaney, M.J., 1999. Maternal care and the development of stress responses. Curr. Opin. Neurobiol. 9 (1), 128-134, http://dx.doi.org/10.1016/ S0959-4388(99)80016-6.

Francis, D.D., Champagne, F.C., Meaney, M.J., 2000. Variations in maternal behaviour are associated with differences in oxytocin receptor levels in the rat. J. Neuroendocrinol. 12, 1145-1148, http://dx.doi.org/10.1046/j.1365-2826. 2000.00599.x.

Ivy, A.S., Brunson, K.L., Sandman, C., Baram, T.Z., 2008. Dysfunctional nurturing behavior in rat dams with limited access to nesting material: a clinically relevant model for early-life stress. Neuroscience 154 (3), 1132-1142, http:// dx.doi.org/10.1016/j.neuroscience.2008.04.019.

Kalinichev, M., Easterling, K.W., Plotsky, P.M., Holtzman, S.G., 2002. Long-lasting changes in stress-induced corticosterone response and anxiety-like behaviors as a consequence of neonatal maternal separation in Long-Evans rats. Pharmacol. Biochem. Behav. 73, 131-140, http://dx.doi.org/10.1016/s00913057(02)00781-5.

Kim, P., Strathearn, L., Swain, J.E., 2016. The maternal brain and its plasticity in humans. Horm. Behav. 77, 113-123, http://dx.doi.org/10.1016/j.yhbeh.2015. 08.001.

Kosten, T.A., Nielsen, D.A., 2014. Litter and sex effects on maternal behavior and DNA methylation of the $\mathrm{Nr} 3 \mathrm{c} 1$ exon $1_{7}$ promoter gene in hippocampus and cerebellum. Int. J. Dev. Neurosci. 36, 5-12, http://dx.doi.org/10.1016/j. ijdevneu.2014.03.010.

Kuhn, C.M., Schanberg, S.M., 1998. Responses to maternal separation: mechanisms and mediators. Int. J. Dev. Neurosci. 16 (2/3), 150-169, http://dx.doi.org/10. 1016/S0736-5748(98)00034-3.

Lajud, N., Roque, A., Cajero, M., Gutiérrez-Ospina, G., Torner, L., 2012. Periodic maternal separation decreases hippocampal neurogenesis without affecting basal corticosterone during the stress hyporesponsive period, but alters HPA axis and coping behavior in adulthood. Psychoneuroendocrinology 37. 410-420, http://dx.doi.org/10.1016/j.psyneuen.2011.07.011.

Lehner, M., Wisłowska-Stanek, A., Maciejak, P., Szyndler, J., Sobolewska, A., Krząścik, P., Płaźnik, A., 2010. The relationship between pain sensitivity and conditioned fear response in rats. Acta Neurobiol. Exp. (Warsz.) 70, 56-66. 
Leon, M., Croskerry, P.G., Smith, G.K., 1978. Thermal control of mother-young contact in rats. Physiol. Behav. 21, 793-811, http://dx.doi.org/10.1016/0031 9384(78)90021-5.

Liu, D., Diorio, J., Tannenbaum, B., Caldji, C., Francis, D., Freedman, A., Sharma, S., Pearson, D., Plotsky, P.M., Meaney, M.J., 1997. Maternal care, hippocampal glucocorticoid receptors, and hypothalamic-pituitary-adrenal responses to stress. Science 277 (5332), 1659-1662, http://dx.doi.org/10.1126/science.277. 5332.1659.

Llorente-Berzal, A., Mela, V., Borcel, E., Valero, M., López-Gallardo, M., Viveros, M.P. Marco, E.M., 2012. Neurobehavioral and metabolic long-term consequences of neonatal maternal deprivation stress and adolescent olanzapine treatment in male and female rats. Neuropharmacology 62, 1332-1341, http://dx.doi.org/ 10.1016/j.neuropharm.2011.07.031.

Lomanowska, A.M., Melo, A.I., 2016. Deconstructing the function of maternal stimulation in offspring development: insights from the artificial rearing model in rats. Horm. Behav. 77, 224-236, http://dx.doi.org/10.1016/j.yhbeh. 2015.05.017.

Lowry, O.H., Rosebrough, N.J., Farr, A.L., Randall, R.J., 1951. Protein measurement. with the Folin phenol reagent. J. Biol. Chem. 193, 265-275.

Macrì, S., Chiarotti, F., Würbel, H., 2008. Maternal separation and maternal care act independently on the development of HPA responses in male rats. Behav. Brain Res. 191, 227-234, http://dx.doi.org/10.1016/j.bbr.2008.03.031.

Macrí, S., Mason, G.J., Würbel, H., 2004. Dissociation in the effects of neonatal maternal separations on maternal care and the offspring's HPA and fear responses in rats. Eur. J. Neurosci. 20, 1017-1024, http://dx.doi.org/10.1111/j. 1460-9568.2004.03541.x.

Maniam, J., Morris, M.J., 2010. Long-term postpartum anxiety and depression-like behavior in mother rats subjected to maternal separation are ameliorated by palatable high fat diet. Behav. Brain Res. 208, 72-79, http://dx.doi.org/10.1016 j.bbr.2009.11.005.

Marcolin, M.L., Benitz, A.N.D., Arcego, D.M., Noschang, C., Krolow, R., Dalmaz, C., 2012. Effects of early life interventions and palatable diet on anxiety and on oxidative stress in young rats. Physiol. Behav. 106 (4), 491-498, http://dx.doi. org/10.1016/j.physbeh.2012.03.025.

Meaney, M.J., Aitken, D.H., Bodnoff, S.R., Iny, L.J., Tatarewicz, J.E., Sapolsky, R.M. 1985. Early postnatal handling alters glucocorticoid receptor concentrations in selected brain regions. Behav. Neurosci. 99 (4), 765-770, http://dx.doi.org/10. 1037/0735-7044.99.4.765.

Molet, J., Heins, K., Zhuo, X., Mei, Y.T., Regev, L., Baram, T.Z., Stern, H., 2016. Fragmentation and high entropy of neonatal experience predict adolescent emotional outcome. Transl. Psychiatry 6, e702, http://dx.doi.org/10.1038/tp 2015.200.

Moore, C.L., Morelli, G.A., 1979. Mother rats interact differently with male and female offspring. J. Comp. Physiol. Psychol. 93 (4), 677-684

Moura, D., Canavarro, M.C., Figueiredo-Braga, M., 2016. Oxytocin and depression in the perinatal period-a systematic review. Arch. Women's Mental Health, http://dx.doi.org/10.1007/s00737-016-0643-3, epub ahead of print.

Murgatroyd, C.A., Nephew, B.C., 2013. Effects of early life social stress on maternal behavior and neuroendocrinology. Psychoneuroendocrinology 38 (2) 219-228, http://dx.doi.org/10.1016/j.psyneuen.2012.05.020.

Murgatroyd, C.A., Peña, C.J., Podda, G., Nestler, E.J., Nephew, B.C., 2015. Early life social stress induced changes in depression and anxiety associated neural pathways which are correlated with impaired maternal care. Neuropeptides 52, 103-111, http://dx.doi.org/10.1016/j.npep.2015.05.002.

Nagasawa, M., Okabe, S., Mogi, K., Kikusui, T., 2012. Oxytocin and mutual communication in mother-infant bonding. Front. Hum. Neurosci. 6, 1-10, http://dx.doi.org/10.3389/fnhum.2012.00031.

Oomen, C.A., Girardi, C.E.N., Cahyadi, R., Verbeek, E.C., Krugers, H., Joëls, M., Lucassen, P.J., 2009. Opposite effects of early maternal deprivation on neurogenesis in male versus female rats. PLoS One 4 (1), e3675, http://dx.doi. org/10.1371/journal.pone.0003675.

Peña, C.J., Champagne, F.A., 2013. Implications of temporal variation in maternal care for the prediction of neurobiological and behavioral outcomes in offspring Behav. Neurosci. 127 (1), 33-46, http://dx.doi.org/10.1037/a0031219.

Pedersen, C.A., Boccia, M.L., 2003. Oxytocin antagonism alters rat dams' oral grooming and upright posturing over pups. Physiol. Behav. 80, 233-241, http://dx.doi.org/10.1016/j.physbeh.2003.07.011.

Pedersen, C.A., Ascher, J.A., Monroe, Y.L., Prange, A.J. Jr., 1982. Oxytocin induces maternal behavior in virgin female rats. Science 216 (4546), 648-650, http:// dx.doi.org/10.1126/science.7071605.

Pereira, M., Ferreira, A., 2016. Neuroanatomical and neurochemical basis of parenting: dynamic coordination of motivational, affective and cognitive processes. Horm. Behav. 77, 72-85, http://dx.doi.org/10.1016/j.yhbeh.2015.08. 005.
Pryce, C.R., Bettschen, D., Feldon, J., 2001. Comparison of the effects of early handling and early deprivation on maternal care in the rat. Dev. Psychobiol. 38 (4), 239-251, http://dx.doi.org/10.1002/dev.1018.

Pryce, C.R., Bettschen, D., Nanz-Bahr, N.I., Feldon, J., 2003. Comparison of the effects of early handling and early deprivation on conditioned stimulus context, and spatial learning and memory in adult rats. Behav. Neurosci. 117 (5), 883-893, http://dx.doi.org/10.1037/0735-7044.117.5.883.

Reeb-Sutherland, B.C., Tang, A.C., 2011. Dissociation between neonatal novelty-induced preferential maternal care and enhancement in cognitive, social, and emotional functions. Behav. Brain Res. 224, 318-325, http://dx.doi. org/10.1016/j.bbr.2011.06.010.

Reeb-Sutherland, B.C., Tang, A.C., 2012. Functional specificity in the modulation of novelty exposure effects by reliability of maternal care. Behav. Brain Res. 226, 345-350, http://dx.doi.org/10.1016/j.bbr.2011.08.047.

Rees, S.L., Steiner, M., Fleming, A.S., 2006. Early deprivation, but not maternal separation, attenuates rise in corticosterone levels after exposure to a novel environment in both juvenile and adult female rats. Behav. Brain Res. 175, 383-391, http://dx.doi.org/10.1016/j.bbr.2006.09.013.

Reis, A.R., Azevedo, M.S., Souza, M.A., Lutz, M.L., Alves, M.B., Izquierdo, I. Cammarota, M., Silveira, P.P., Lucion, A.B., 2014. Neonatal handling alters the structure of maternal behavior and affects mother-pup bonding. Behav. Brain Res. 265, 216-228, http://dx.doi.org/10.1016/j.bbr.2014.02.036.

Rivarola, M.A., Suárez, M.M., 2009. Early maternal separation and chronic variable stress in adulthood changes the neural activity and the expression of glucocorticoid receptor in limbic structures. Int. J. Dev. Neurosci. 27, 567-574, http://dx.doi.org/10.1016/j.ijdevneu.2009.06.007.

Scanlan, V.F., Byrnes, E.M., Bridges, R.S., 2006. Reproductive experience and activation of maternal memory. Behav. Neurosci. 120 (3), 676-686, http://dx. doi.org/10.1037/0735-7044.120.3.676.

Singh-Taylor, A., Korosi, A., Molet, J., Gunn, B.G., Baram, T.Z., 2015. Synaptic rewiring of stress-sensitive neurons by early-life experience: a mechanism for resilience? Neurobiol. Stress 1, 109-115, http://dx.doi.org/10.1016/j.ynstr. 2014.10.007.

Stamatakis, A., Kalpachidou, T., Raftogianni, A., Zografou, E., Tzanou, A., Pondiki, S., Stylianopoulou, F., 2015. Rat dams exposed repeatedly to a daily brief separation from the pups exhibit increased maternal behavior, decreased anxiety and altered levels of receptors for estrogens (ER $\alpha, E R \beta)$, oxytocin and serotonin (5-HT1A) in their brain. Psychoneuroendocrinology 52, 212-228, http://dx.doi.org/10.1016/j.psyneuen.2014.11.016.

Stern, J.M., 1997. Offspring-induced nurturance: animal-human parallels. Dev. Psychobiol. 31, 19-37, http://dx.doi.org/10.1002/(SICI)10982302(199707)31:1<19:AID-DEV3>3.0. CO;2-X

Suchecki, D., Rosenfeld, P., Levine, S., 1993. Maternal regulation of the hypothalamic-pituitary-adrenal axis in the infant rat: the roles of feeding and stroking. Dev. Brain Res. 75, 185-192.

Tang, A.C., Akers, K.G., Reeb, B.C., Romeo, R.D., McEwen, B.S., 2006. Programming social, cognitive, and neuroendocrine development by early exposure to novelty. Proc. Natl. Acad. Sci. U. S. A. 103, 15716-15721, http://dx.doi.org/10. 1073/pnas.0607374103.

Uvnäs-Moberg, K., 1997. Physiological and endocrine effects of social contact. Ann. N. Y. Acad. Sci. 807 (1), 146-163, http://dx.doi.org/10.1111/j.1749-6632.1997. tb51917.x.

Viveros, M.P., Llorente, R., Díaz, F., Romero-Zerbo, S.Y., Bermudez-Silva, F.J. Rodríguez de Fonseca, F., Argente, J., Chowen, J.A., 2010. Maternal deprivation has sexually dimorphic long-term effects on hypothalamic cell-turnover, body weight and circulating hormone levels. Horm. Behav. 58 (5), 808-819, http:/I dx.doi.org/10.1016/j.yhbeh.2010.08.003.

Wong, J.H., Brummelte, S., Galea, L.A., 2011. Elevated corticosterone levels during the first postpartum period influence subsequent pregnancy outcomes and behaviours of the dam. J. Neuroendocrinol. 23 (11), 1156-1165, http://dx.doi. org/10.1111/j.1365-2826.2011.02169.x.

Zalosnik, M.I., Pollano, A., Trujillo, V., Suárez, M.M., Durando, P.E., 2014. Effect of maternal separation and chronic stress on hippocampal-dependent memory in young adult rats: evidence for the match-mismatch hypothesis. Stress 17 (5), 445-450, http://dx.doi.org/10.3109/10253890.2014.936005.

van Hasselt, F.N., Cornelisse, S., Zhang, T.Y., Meaney, M.J., Velzing, E.H., Krugers, H.J., Joëls, M., 2012. Adult hippocampal glucocorticoid receptor expression and dentate synaptic plasticity correlate with maternal care received by individuals early in life. Hippocampus 22, 255-266, http://dx.doi.org/10.1002/hipo.20892.

von Poser Toigo, E.P., Diehl, L.A., Ferreira, A.G.K., Mackendanz, V., Krolow, R. Benitz, A.N.D., Noschang, C., Huffell, A.P., Silveira, P.P., Wyse, A.T.S., Dalmaz, C., 2012. Maternal depression model: long-lasting effects on the mother following separation from pups. Neurochem. Res. 37, 126-133, http://dx.doi.org/10. 1007/s11064-011-0590-3. 